\title{
Impact of Long-Term Filter Cigarette Usage on Lung and Larynx Cancer Risk: A Case-Control Study 1.2
}

\author{
Ernst L. Wynder, M.D., ${ }^{3}$ and Steven D. Stellman, Ph.D. ${ }^{4,5}$
}

\begin{abstract}
A case-control study was conducted among 1,034 white male and female hospital patients with histologically proved lung cancer (Kreyberg type I) or larynx cancer. After adjustment for duration of the smoking habit, inhalation, and butt length, relative risks of developing lung or larynx cancer were consistently lower among long-term smokers of filter cigarettes than among smokers of nonfilter cigarettes, irrespective of quantity smoked. Relative risks in all groups declined with increased years of smoking cessation. The observed risk reduction among current smokers of filter cigarettes was consistent with that expected, considering that these persons had smoked the older high-tar nonfilter cigarettes for a large proportion of their lives.J Natl Cancer Inst 62: 471-477, 1979.
\end{abstract}

Although cigarette smoking is recognized as the major causative factor of lung and larynx cancer in both men and women (1), elimination of cigarette smoking does not at present appear to be a social possibility. Therefore, as Gori (2) has pointed out, alternative strategies must be sought as a humane but interim approach to the complex problem of preventing tobacco-related disease. Two such strategies continue to be explored widely: $a$ ) persuading segments of the population to reduce their consumption of cigarettes or to quit altogether (behavioral), and $b$ ) modifying the cigarette itself to produce a "less harmful cigarette" (managerial). The effects of both approaches on the risk of developing tobacco-related cancer have been intensively studied for a number of years. In this paper we examine the impact that the less harmful cigarette has thus far had on the risk of developing lung or larynx cancer, and we attempt to predict the future disease patterns that may emerge from continued application of the managerial approach to cancer prevention.

The rationale underlying this assessment is the doseresponse effect observed in both prospective and retrospective studies; the greater the exposure (as measured, e.g., by the average number of cigarettes smoked per day or by duration of the smoking habit), the greater the risk of lung or other tobacco-related cancers (3-6). Thus as exposure decreases, either by smoking fewer cigarettes or by smoking cigarettes significantly lower in yield of tumorigenic components, a proportionately lower risk of developing tobacco-related cancers should be expected.

In this regard, two major events have occurred over the past 20 years: Consumption of cigarettes with lower $\operatorname{tar}^{6}$ has increased (7-10), and the tumorigenic potential of tar has decreased $(10-12)$. Earlier studies have shown that a lower lung and larynx cancer risk exists among long-term smokers of filter cigarettes than among smokers of nonfilter brands (13-16). We provide further evidence, encouraging in light of the growing popularity of lower tar cigarettes.

\section{MATERIALS AND METHODS}

The data constitute a portion of that collected in an ongoing retrospective study of tobacco-related cancer.

With the use of a standard questionnare, interviews were conducted from 1969 to 1976 in six U.S. cities by personnel who had undergone a detailed and uniform training period at our institute. Approximately onethird of all interviewed patients were at Memorial Hospital, and decreasingly smaller numbers were in various hospitals in Houston, Los Angeles, New York, Birmingham, Miami, and New Orleans. Interviewers visited $93 \%$ of the coherent lung and larynx cancer patients admitted to these hospitals.

The numbers of cancer patients and controls are shown in table 1 with their age distributions. There were 684 lung cancer cases and 350 larynx cancer cases. All patients had histopathologic confirmation of diagnosis. For the analysis in this paper, only Kreyberg type I lung cancer (squamous and oat cell types) was considered because this type has been shown to exhibit

AbBreviations uSED: LTFS=long-term filter cigarette smoker(s); NFS $=$ nonfilter cigarette smoker(s).

\footnotetext{
${ }^{1}$ Received March 29, 1978; accepted September 3, 1978.

${ }^{2}$ Supported by Public Health Service contract N01-CP55666 and grant CAl7613 from the National Cancer Institute. Computations were performed in part at the Courant Computing and Mathematics Center (New York University), which is supported by U.S. Department of Energy contract EY-76-C-02-3077.

${ }^{3}$ Division of Epidemiology, Naylor Dana Institute for Disease Prevention, American Health Foundation, 320 East 43d St., New York, N.Y. 10017.

${ }^{4}$ Division of Biostatistics, Naylor Dana Institute for Disease Prevention.

${ }^{5}$ We thank Mr. Harland Austin and Ms. Nancy Saphier for excellent statistical and programming assistance. We also acknowledge the contributions of the following institutions and individuals-New York, N.Y.: Memorial Hospital, Dr. E. Beattie; Mount Sinai Medical Center, Dr. Sheldon Kupfer; Manhattan Veterans Administration Hospital, Dr. Charles Rednor and Dr. Norton Spritz; Francis Delafield Hospital, Ms. Esther Austin; Metropolitan Hospital, Dr. Sigmunde Hirsche; St. Luke's Hospital, Ms. Evelyn Peck. Miami, Fla.: Miami Veterans Hospital and University of Miami Hospital Center, Dr. George Baum. Birmingham, Ala.: University Hospital, Dr. Peter B. Peacock. Houston, Tex.: M.D. Anderson Hospital and Tumor Institute, Dr. Rulon W. Rawson. Los Angeles, Calif.: University of California at Los Angeles Hospital, Dr. Lester Breslow. New Orleans, La.: Veterans Administration Hospital and Charity Hospital, Dr. Alton Ochsner.

6 Total particulate matter (TPM) refers to the material separated from the gaseous portion of cigarette smoke by a Cambridge filter, while "tar" is defined and measured by the U.S. Federal Trade Commission as TPM less moisture and nicotine.
} 
TABLE 1.-Number of cancer and control patients who were either lifetime nonsmokers, current smokers, or ex-smokers. by age and sex

\begin{tabular}{|c|c|c|c|c|c|c|}
\hline \multirow{2}{*}{ Age, yr } & \multicolumn{2}{|c|}{$\begin{array}{l}\text { Lung }^{a} \text { cancer } \\
\text { patients }\end{array}$} & \multicolumn{2}{|c|}{$\begin{array}{c}\text { Laryn }^{b} \text { cancer } \\
\text { patients }\end{array}$} & \multicolumn{2}{|c|}{ Controls } \\
\hline & Male & Female & Male & Female & Male & Female \\
\hline $\begin{array}{l}<50 \\
50-59 \\
60-69 \\
70-89 \\
\quad \text { Total }\end{array}$ & $\begin{array}{r}72 \\
191 \\
215 \\
79 \\
557\end{array}$ & $\begin{array}{r}29 \\
46 \\
32 \\
20 \\
127\end{array}$ & $\begin{array}{r}41 \\
108 \\
93 \\
44 \\
286\end{array}$ & $\begin{array}{r}15 \\
22 \\
24 \\
3 \\
64\end{array}$ & $\begin{array}{r}1,533 \\
1,402 \\
1,318 \\
582 \\
4,835\end{array}$ & $\begin{array}{r}1,617 \\
1,301 \\
1,104 \\
690 \\
4,712\end{array}$ \\
\hline
\end{tabular}

a Kreyberg type I.

${ }^{b}$ Glottic and supraglottic types.

the strongest dose response of all tobacco-related cancers $(6,14)$. The larynx cancer cases included both glottic and supraglottic types because both have been shown to be equally related to tobacco usage (13).

Controls were selected on the basis of absence of a history of tobacco-related disease. Tobacco-related disease was defined as a cancer of lung, larynx, mouth, esophagus, or bladder [which comprised the cases in our previous report (6)]; cancer of the pancreas, liver, or kidney; myocardial infarction; stroke, peripheral vascular disease, or abdominal aortic aneurysm; chronic bronchitis or chronic obstructive pulmonary disease; gastric ulcer; or cirrhosis of the liver. The diagnoses of 9,547 eligible controls were distributed as follows (numbers in parentheses are percentages for males and females, respectively): cancer of the stomach $(2,2)$, colon or rectum $(7,5)$, prostate gland $(6,0)$, breast $(0$, $13)$, cervix $(0,10)$, or skin, including melanoma $(6,4)$; leukemia, lymphoma, or Hodgkin's disease $(7,4)$; other cancers, e.g., cancer of the male or female reproductive organs $(9,11)$; benign neoplastic diseases $(11,11)$; fractures $(8,6)$; or other nonneoplastic diseases, e.g., burns, infections, or duodenal ulcers $(44,34)$.

The major index of response to cigarette smoking was expressed as the relative risk, defined as the ratio of the incidence of lung or larynx cancer among smokers to its incidence among nonsmokers. Point

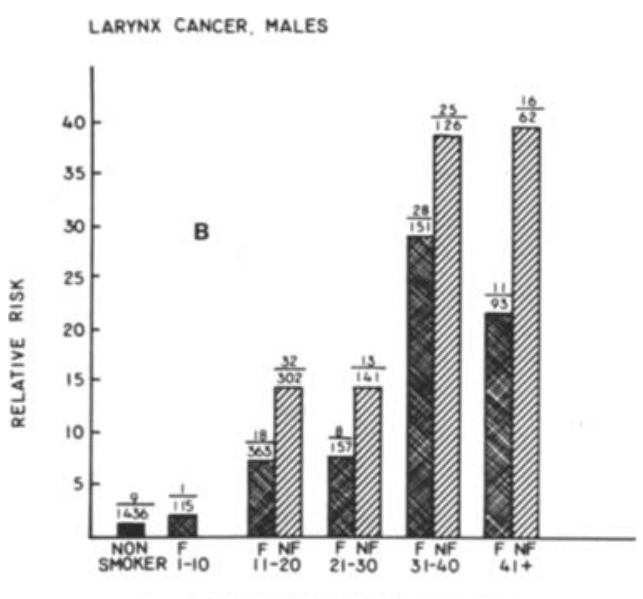

NO. OF CIGARETTES SMOKED PER DAY

LARYNX CANCER, FEMALES

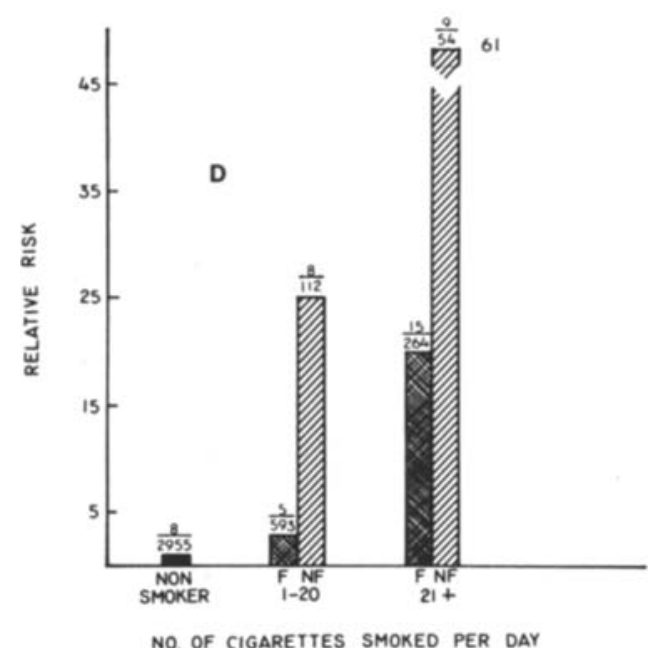

TEXT-FIGuRE 1.-Age-adjusted relative risk of lung or larynx cancer for LTFS and NFS by quantity smoked. Fraction $=$ No. cases $/$ No. controls, $F=$ filter cigarettes, $\mathbf{N F}=$ nonfilter cigarettes. A) Lung cancer, males; No. cases $=143$ L.TFS, 150 NFS. B) Larynx cancer, males; No. cases $=66$ LTFS, 86 NFS. C) Lung cancer, females; No. cases $=50$ LTFS, 13 NFS. D) Larynx cancer, females; No. cases=20 LTFS, 17 NFS. 
estimates of relative risk were made by means of odds ratios; potentially confounding variables (e.g., age) were controlled by use of either the Mantel-Haenszel method (17) or the Miettinen confounder score method (18). Interval estimates of relative risk were made by the method of Gart (19).

This study included all interviewed white patients who were either nonsmokers (never smoked any tobacco product regularly), ex-smokers (quit at least 1 year prior to interview), or current cigarette smokers. Persons who had regularly smoked only cigars or pipes were excluded, but not cigarette smokers who also used cigars or pipes. To assure that the known latency period for most tobacco-related cancers was exceeded, we restricted the smoker and ex-smoker groups to people who had smoked cigarettes for at least 20 years.

\section{RESULTS}

\section{Relative Risks Among LTFS and NFS}

Age-adjusted relative risks were estimated separately for LTFS (defined as present smokers who used filter cigarettes currently and for at least 10 years) and NFS (defined as present smokers whose current brand was nonfilter). Age categories used in the adjustment were: $20-49,50-59,60-69$, and $70-89$ years. Results of these calculations are displayed for both lung and larynx cancer in text-figure 1 . In these dose-response curves, the estimated relative risk is plotted against the quantity smoked (defined as the average number of cigarettes of the current brand smoked per day). Among both females and males, the risk for both lung and larynx cancer among LTFS was lower than that of NFS at each of the five quantity levels in which data were grouped.

Table 2 shows the relative risks for LTFS, expressed as a percentage of the risk for NFS, by sex and quantity of cigarettes smoked daily. Percent reduction of risk is obtained by subtracting this quantity from $100 \%$. Among male LTFS, reduction of risk ranged from 11 to $39 \%$ for lung cancer and from 25 to $49 \%$ for larynx cancer. Substantial lowering of risk was also calculated for female LTFS; the one exception was

TABLE 2.-Relative risk of lung or larynx cancer for LTFS, ${ }^{a}$ as a percentage of the relative risk for NFS, by sex and quantity smoked

\begin{tabular}{|c|c|c|c|c|}
\hline \multirow{3}{*}{$\begin{array}{l}\text { No. of } \\
\text { cigarettes } \\
\text { smoked/ } \\
\text { day }\end{array}$} & \multicolumn{4}{|c|}{ Cancer site } \\
\hline & \multicolumn{2}{|c|}{ Lung } & \multicolumn{2}{|c|}{ Larynx } \\
\hline & Male, $\%$ & Female, \% & Male, \% & Female, $\%$ \\
\hline $1-10$ & 61 & 38 & - & - \\
\hline $1-20$ & - & - & - & 11 \\
\hline $11-20$ & 89 & 69 & 51 & - \\
\hline $21-30$ & 71 & 79 & 53 & - \\
\hline $21+$ & - & - & - & 33 \\
\hline $31-40$ & 66 & - & 75 & - \\
\hline $31+$ & - & 103 & - & - \\
\hline $41+$ & 86 & - & 55 & - \\
\hline
\end{tabular}

${ }^{a}$ Defined as present smokers who have used filter cigarettes for $\geq 10$ years.

${ }^{b}$ Defined as present smokers whose current brand is nonfilter.
TABLE 3.-Estimated relative risk of lung and larymx cancer among NFS, relative to LTFS, after adjusting for various factors

\begin{tabular}{|c|c|c|c|}
\hline Sex & $\begin{array}{c}\text { Adjustment } \\
\text { factors }^{a}\end{array}$ & Odds ratio & $\begin{array}{c}\text { 95\% Confidence } \\
\text { interval }\end{array}$ \\
\hline \multicolumn{4}{|c|}{ Lung cancer } \\
\hline $\begin{array}{l}\text { Male } \\
\text { Male } \\
\text { Female } \\
\text { Female } \\
\end{array}$ & $\begin{array}{l}\mathrm{D}, \mathbf{Q} \\
\mathrm{A}, \mathbf{Q} \\
\mathrm{D}, \mathbf{Q} \\
\mathrm{A}, \mathbf{Q}\end{array}$ & $\begin{array}{l}1.19 \\
1.26 \\
1.29 \\
1.37 \\
\end{array}$ & $\begin{array}{l}(0.92-1.55) \\
(0.97-1.64) \\
(0.67-2.47) \\
(0.72-2.60) \\
\end{array}$ \\
\hline \multicolumn{4}{|c|}{ Larynx cancer } \\
\hline $\begin{array}{l}\text { Male } \\
\text { Male } \\
\text { Female } \\
\text { Female }\end{array}$ & $\begin{array}{l}\text { D, Q } \\
\text { D, Q, Alc } \\
\text { A, Q } \\
\text { D, Q } \\
\text { D, Q, Alc } \\
\text { A, Q }\end{array}$ & $\begin{array}{l}1.65 \\
1.49 \\
1.71 \\
4.19 \\
3.97 \\
4.34\end{array}$ & $\begin{array}{l}(1.16-2.34) \\
(1.05-2.10) \\
(1.21-2.41) \\
(2.66-6.61) \\
(2.04-7.70) \\
(2.27-8.31)\end{array}$ \\
\hline
\end{tabular}

a By Mantel-Haenszel method, adjusted for duration (D): 20-29, 30-39, 40-49, 50-59, 60+ years; average No. of cigarettes smoked per day (Q): $1-10,11-20,21-30,31-40,41+$; age (A): 20-49, $50-59,60-69,70-89$ years; alcohol consumption (Alc): none, 1-6 oz/day, $7+o z / d a y$. For females, due to the smaller number of cases, the D categories $50-59$ and $60+$ were combined, as were the $Q$ categories $31-40$ and $41+$.

probably attributable to the small number of cases in that category.

Adjustment for duration and quantity smoked.-Although adjusted for age, the foregoing risk estimates may be influenced by additional confounding by duration of smoking habit, even though age and duration are strongly correlated. This would be true, for example, if LTFS began smoking earlier in life than did NFS of the same age. Additional risk estimates were made in which both habit duration and cigarette quantity were controlled, and they were compared with corresponding estimates in which both age and quantity were controlled. Because we were adjusting for possible differences between LTFS and NFS, the risks were calculated with LTFS (rather than nonsmokers) as the referent. Results are presented in table 3 , in which the odds ratios and $95 \%$ confidence intervals are given.

Adjustment for other smoking intensity variables. Because tar and nicotine levels of cigarettes are highly correlated $(10)$, it has been suggested that persons who switch to cigarettes with a lower tar level may subsequently adjust their smoking habits to compensate for the concomitantly lower nicotine level. This compensation may be manifested by an increase in the number of cigarettes smoked per day, deeper inhalation, or shorter butt length (indicating a greater portion of each cigarette smoked). Odds ratios were calculated for lung cancer by use of Miettinen's method (18), in which the following variables were all controlled simultaneously: average daily quantity of cigarettes smoked and habit duration (continuous), education (eight levels), inhalation (four levels), butt length (four levels), and city (six levels). The resulting risk estimates, based on a summary over 10 strata of the confounder score, were not significantly different from those reported in table 3 .

Adjustment for alcohol consumption.-Although the risk for lung cancer is greater than that for larynx 
cancer among smokers (relative to nonsmokers) (6), table 3 shows that the reduction in risk observed among LTFS relative to NFS was actually greater for larynx cancer. Because larynx cancer is related to use of alcohol as well as to cigarette consumption, potential confounding by alcohol consumption was considered. Among controls, for example, NFS were twice as likely as LTFS to be heavy drinkers of alcohol ( 7 or more oz/day). The larynx cancer risks in table 3 , after adjustment for duration of smoking, quantity smoked, and alcohol consumption, were reduced to 1.49 for men and 3.97 for women when this confounding was removed but were still significantly greater than 1 .

\section{Effect of Smoking Cessation on Cancer Risk}

Because maximum reduction in cancer risk is achieved by reducing tar intake to zero, i.e., quitting smoking altogether, relative risk estimates were made for ex-

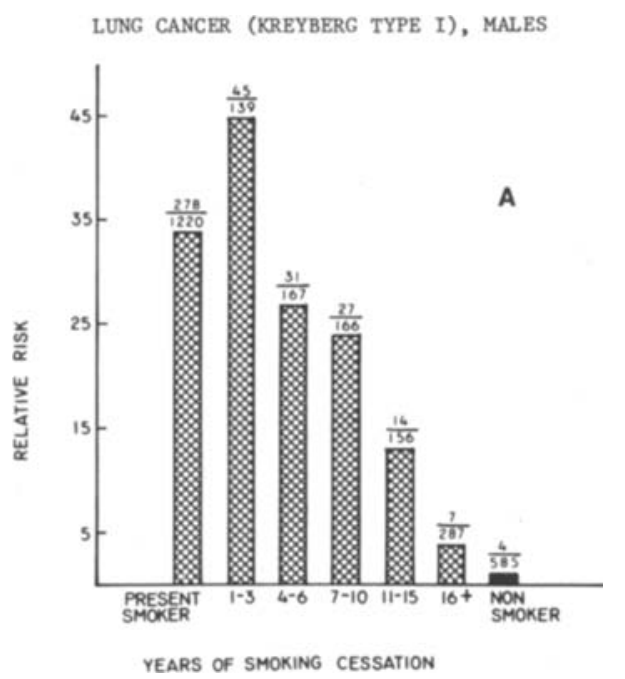

LUNG CANCER (KREYBERG TYPE I), FEMALES

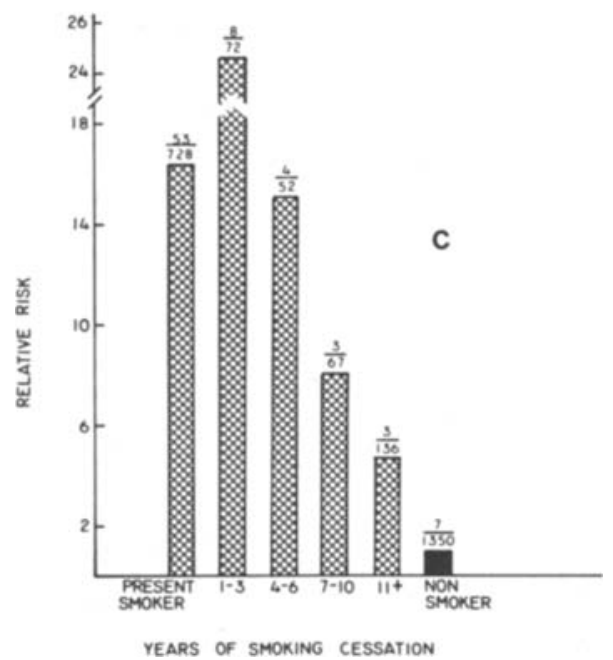

smokers in several age strata. In these calculations it was not possible to discriminate between former NFS and LTFS, because few of the latter had quit smoking for a significant period of time. As observed previously $(6,13)$, relative risk declined with years of cessation. Because the reduction of risk was appreciably greater for people 50-69 years old than for those 70 or more years old, the relative risks for persons 50-69 only (stratified into two groups, 50-59 and 60-69, and reported as a combined risk estimate) were plotted against years of cessation in text-figure 2 . This age group included more than two-thirds of all lung and larynx cancer patients.

The relevance of smoking cessation, particularly in this age group, to use of the less harmful cigarette is assessed by two observations (text-fig. 2). First, male long-term cigarette smokers must have ceased the habit for at least 3 years before any decline in risk could be expected. The sizable increase in risk among males during the first 3 years after cessation may be attrib-


TEXT-FIGURE 2.-Age-adjusted risk of lung or larynx cancer for ex-smokers (50-69 years old) by years of cessation. Fraction $=$ No. cases $/$ No. controls. A) Lung cancer, males; No. cases $=406$. B) Larynx cancer, males; No. cases $=201$. C) Lung cancer, females; No. cases $=78$. D) Larynx cancer, females; No. cases $=46$. 
utable to the failure of smokers with emerging signs of clinical illness to seek medical attention until after quitting. Second, 10-15 years of cessation are required before the long-term smoker's risk approaches that of a nonsmoker. Therefore, at least this much time must elapse for a long-term smoker to receive maximum benefit from switching to lower tar cigarettes. This was our rationale for restricting the LTFS group to persons who had continuously smoked filter cigarettes for at least 10 years.

\section{DISCUSSION}

Whether calculated as a single summary estimate or as a dose-response curve, the data consistently point to reductions in risk for lung cancer and even larger reductions for larynx cancer risk among LTFS. As stated previously, the maximum risk reduction that a long-term smoker can expect is achieved only through complete cessation of smoking. One who switches from nonfilter to filter cigarettes must necessarily experience a more modest risk reduction than an ex-smoker over the same time period. Average tar levels of filter cigarettes have been about two-thirds those of nonfilter cigarettes for over a decade, and the tar levels for both have declined roughly in parallel; thus a $20-30 \%$ lowering in risk may reasonably be expected at the present time and was about what was observed.

The following is a discussion of current and future trends in cigarette composition and smoking behavior that may soon influence the expected patterns of tobacco-related cancers.

\section{Cigarette Variables}

Changes in tar levels with time.-When the first major epidemiologic studies linking lung cancer and cigarette smoking appeared in 1950 (5), the average cigarette yielded about $40 \mathrm{mg}$ tar. Since that time, tar levels have fallen considerably. Text-figure 3 demonstrates that tar levels of both filter and nonfilter cigarettes continue to fall, and that even today's nonfilter cigarette produces one-third less tar than the nonfilter cigarette of a generation ago (20). This reduction in tar has occurred not only in the United States but throughout most of the world $(10-12,21-24)$, as shown in studies by Kuhn and Klus (25) in Austria, Todd in England (26), Ledez in France (personal communication), Timm in Germany (27), and Hoffmann in Canada (unpublished observations).

Changes in tar activity.-Chemical and biological experiments have indicated that tars of present-day cigarettes have lower carcinogenicity per gram than tars of 25 years ago $(4,10,11)$. This lowered activity, coupled with reduced total yield per cigarette, has undoubtedly contributed to a reduction in cancer risk in some populations, as observed in this and other studies (24).

\section{Smoking Variables ,}

Changes in filter cigarette consumption.-It is not sufficient that some of the available cigarettes become potentially less harmful in order to bring about a measurable lowering of disease incidence. Smokers must also switch to those cigarettes in preference to higher tar brands. This appears to be the trend. By 1976 nearly $90 \%$ of all cigarettes sold in the United States were filter brands $(20,24)$. The past 5 years have witnessed the emergence of low-tar $(<15 \mathrm{mg})$ cigarettes, which have captured more than $16 \%$ of the market. This trend is illustrated in text-figure 4 in which the market share of all cigarettes yielding less than $15 \mathrm{mg}$ tar is plotted for the 10-year period 1967-76. The growing usage of these cigarettes will probably have a continuing effect on reducing the average daily tar intake and concomitant disease risk.

Changes in lifetime tar consumption.-Our studies have not yet included persons who have smoked lower tar cigarettes exclusively. Text-figure 5 shows a model calculation of the proportion of a person's lifetime

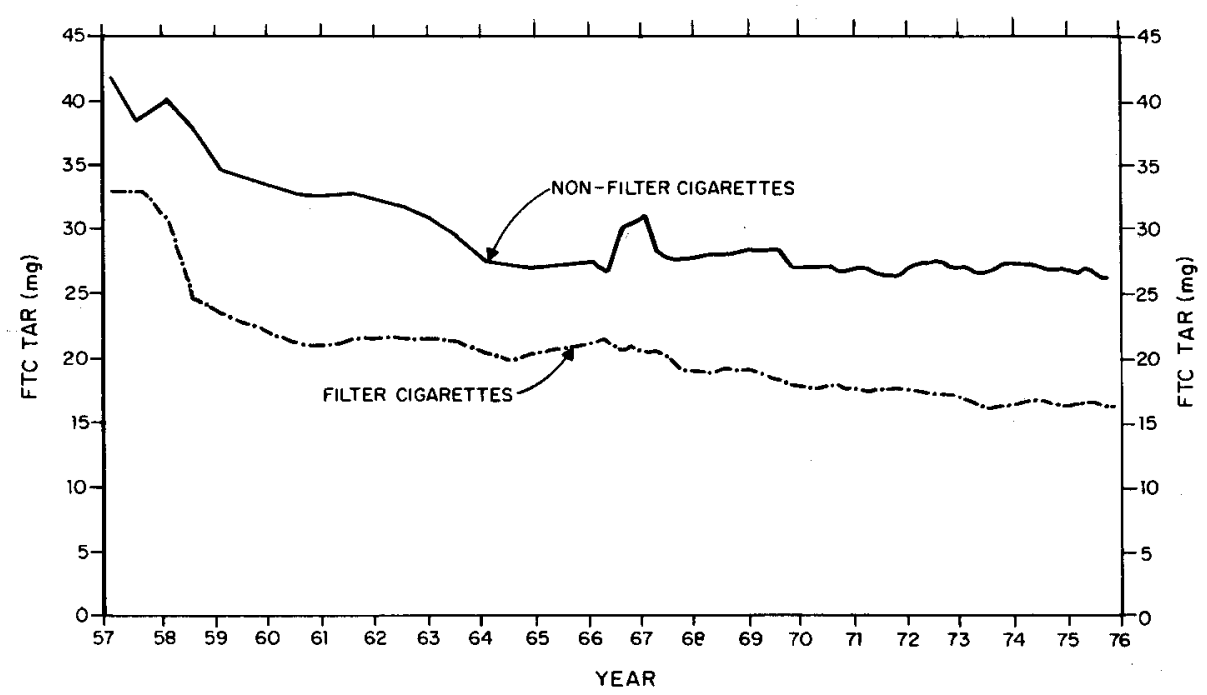

TeXT-FIGURE 3.-Sales-weighted average tar delivery of U.S. filter and nonfilter cigarettes, 1957-76. FTC=Federal Trade Commission. 


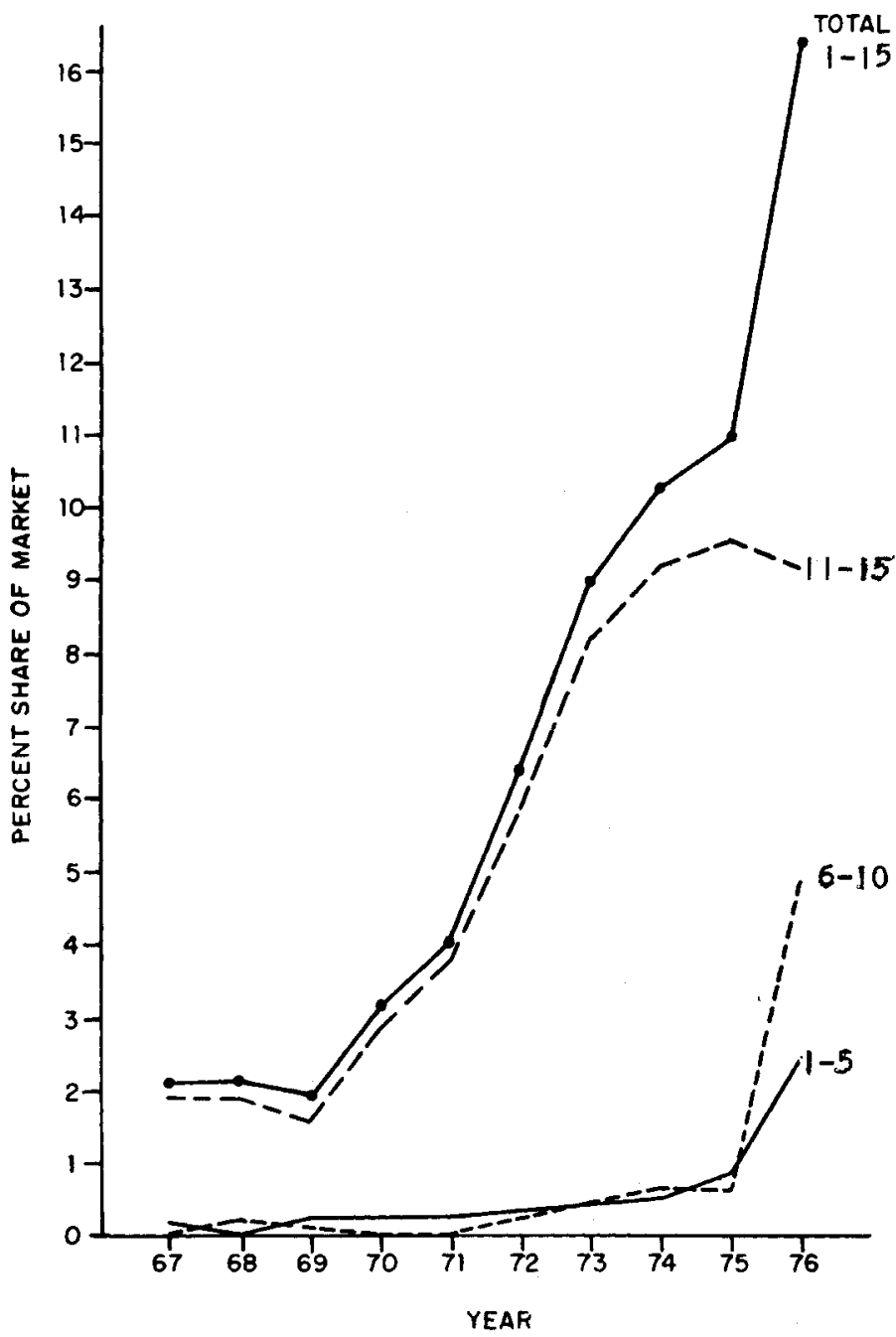

TeXT-Figure 4,-Percent market share for low-tar cigarettes, 1967-76. cigarette [(10, 28-30); Hill P: Unpublished observations]. However, long-term epidemiologic studies, including this one, have not shown differences between LTFS and NFS, either among lung or larynx cancer patients or controls, in either the number of cigarettes smoked or subjective inhalation response (though the lung and larynx cancer patients as a group invariably consumed more cigarettes than did the controls) $(6,28)$. In this study, adjustment for inhalation and butt length did not bring about significant changes in risk estimates.

Objective comparisons of levels of nicotine, its major metabolite cotinine, and carboxyhemoglobin in the sera of long-term smokers are clearly needed and are now in progress in our laboratory. They may help to resolve this behavioral issue by determining whether long-term compensation for a low-nicotine cigarette might lead to greater tar consumption.

\section{Alternative Strategles,}

Although development of a less harmful cigarette has apparently had some success in lowering the risk of lung and larynx cancer, it must not be considered a complete prescription for the prevention of these and other tobacco-related diseases. Additional approaches are needed, particularly preventive education of young presmokers and cessation programs for current smokers. At present, antismoking education is making little headway with our youth. The number of boys who begin smoking has remained constant over the last decade, and the number of girls taking up the habit has doubled (31). New approaches to health education of the young are needed, such as the Know Your Body (KYB) program initiated by our institute, whereby each child is involved in health promotion programs (32, 33). Antismoking propaganda among adults has been more successful for men than for women; among the

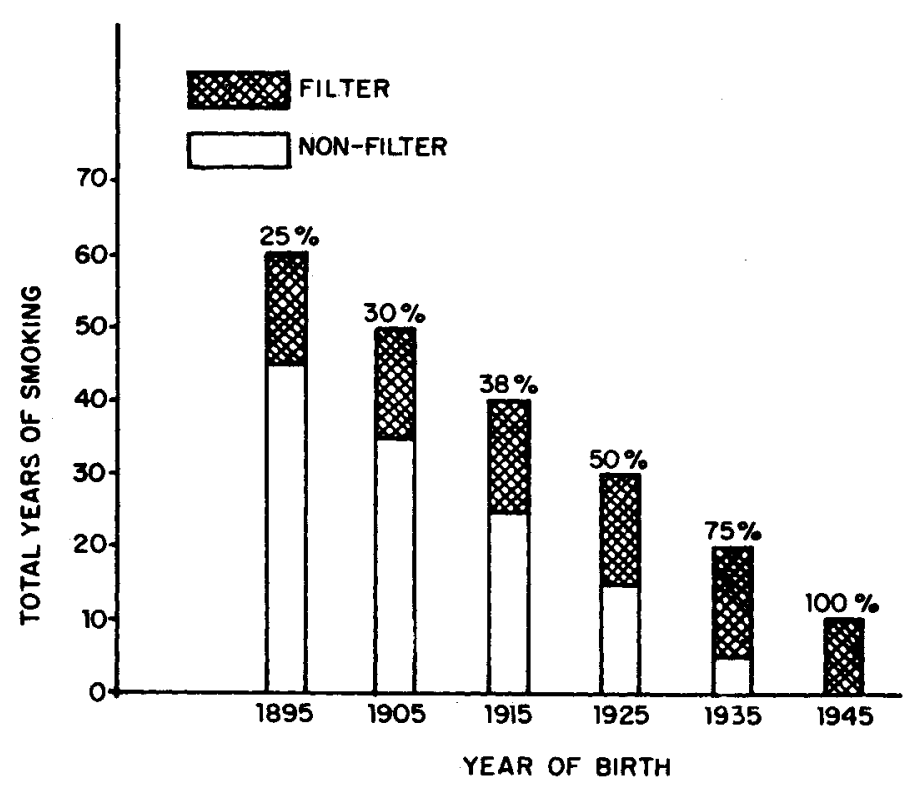

TEXT-FIGURE 5.-Filter cigarette usage as a percentage of total smoking experience, by birth cohort. spent smoking filter cigarettes, on the assumption that a typical smoker began at age 20 and switched to filter cigarettes in 1960 when these brands achieved widespread popularity. About two-thirds of lung cancer patients currently fall between ages 50 and 68 and, as text-figure 5 indicates, could have used filter cigarettes for no more than $50 \%$ of their total smoking years. Considering that the average lung or larynx cancer patient is between 56 and 60 years old and has smoked cigarettes for an average of $40-50$ years, the risk for developing a smoking-related cancer today probably depends on a history that included both old and new types of cigarettes. The relative risks should be even lower in the future among persons who will have smoked filter cigarettes all their lives.

Changes in smoking behavior.-Because tar and nicotine levels in cigarette smoke are strongly correlated (10), the simultaneous reduction of these two components might be compensated behaviorally by increased exposure, e.g., deeper inhalation, more frequent puffing, and leaving shorter butts. Some short-term studies have demonstrated that all three methods can be used by the same smoker to adjust to the new lower tar 
more educated groups of men a significant percentage have been able to stop smoking on their own (9). Smoking cessation clinics have also had some success $(34,35)$. Nevertheless, more than 40 million adults continue to smoke in spite of all evidence presented to them of its adverse effects. As long as society condones smoking, young people will take up the habit, and many adults will continue. Obviously, better antismoking propaganda, improved smoking cessation programs, and development of even less harmful cigarettes are needed.

\section{REFERENCES}

(1) U.S. Department of Health, Education, and Welfare: Smoking and Health. Report of the Advisory Committee to the Surgeon General of the Public Health Service. Public Health Serv Bull No. 1103. Washington, D.C.; U.S. Govt Print Off, 1964

(2) GORI GB: Low-risk cigarettes: A prescription. Science 194:12431247, 1976

(3) Hammond EC: Smoking in relation to death rates of one million men and women. Natl Cancer Inst Monogr 19:129-204, 1966

(4) U.S. Department of Health, Education, and Welfare: The Health Consequences of Smoking. (CDC) 74-8704. Washington, D.C.: U.S. Govt Print Off, 1974

(5) Wynder EL, Graham EA: Tobacco smoking as a possible etiologic factor in bronchiogenic carcinoma. JAMA 143:329336,1950

(6) Wynder EL, Stellman SD: Comparative epidemiology of tobacco-related cancers. Cancer Res 37:4608-4622, 1977

(7) U.S. Department of Health, Education, and Welfare: The Adult Use of Tobacco, 1975. Atlanta: Center for Disease Control, Bureau of Health Education, 1976

(8) Wynder EL, Hoffmann D: Tobacco and tobacco smoke. Semin Oncol 3:5-15, 1976

(9) Wynder EL, Covey LS, Mabuchi K: Current smoking habits by selected background variables: Their effect on future disease trends. Am J Epidemiol 100:168-177, 1974

(10) WEBER KH: Recent changes in tobacco products and their acceptance by the consumer. In Proceedings of the Sixth International Tobacco Scientific Congress, Tokyo, Japan, 1976. Coresta Information Bull (special): $15-30,1976$

(11) Wynder EL, Hofrmann D: Tobacco and Tobacco Smoke: Studies in Experimental Carcinogenesis. New York: Academic Press, 1967

(12) - Experimental tobacco carcinogenesis. Science 162:862871,1968

(13) Wynder EL, Covey LS, Mabuchi K, et al: Environmental factors in cancer of the larynx: A second look. Cancer 38:15911601,1976

(14) Wynder EL, Mabuchi K, Beattie EJ: The epidemiology of lung cancer: Recent trends. JAMA 213:2221-2228, 1970

(15) BROSS IJ, GibSON R: Risk of lung cancer in smokers who switch to filter cigarettes. Am J Public Health 58:1396-1402, 1968

(16) Hammond EC, Garfinkel L, Seidman H, et al: Tar and nico- tine content of cigarette smoke in relation to death rates. Environ Res 12:263-274, 1976

(17) Mantel N, Haenszel W: Statistical aspects of the analysis of data from retrospective studies of disease. J Natl Cancer Inst 22:719-748, 1959

(18) MieTtinen OS: Stratification by a multivariate confounder score. Am J Epidemiol 104:609-620, 1976

(19) GART JJ: Point and interval estimation of the common odds ratio in the combination of $2 \times 2$ tables with fixed marginals. Biometrika 57:471-475, 1970

(20) Maxwell JC JR: The 1976 Maxwell report. Tobacco Reporter 103:16-17, 54-55, 1976

(21) Hoffmann D, Schmeltz I, Hecht SS, et al: Chemical studies on tobacco smoke. XXXIX. On the identification of carcinogens, tumor promoters and carcinogens in tobacco smoke. In Proceedings of the Third World Conference on Smoking and Health (Wynder EL, Hoffmann D, Gori GB, eds), vol 1 Washington, D.C.: U.S. Govt Print Off, 1976, pp 125-145

(22) WYNDER EL, HofFMANN D: Less harmful ways of smoking. J Natl Cancer Inst 48:1749-1758, 1972

(23) Wynder EL, Hofrmanin D, Gori BG, eds: Proceedings of the Third World Congress on Smoking and Health, vol 1 . Washington, D.C.: U.S. Govt Print Off, 1976

(24) Wynder EL, Hecht S, eds: Lung cancer. UICC Technical Report Series, vol 25. Geneva: Union Internationale Contre le Cancer, 1976

(25) KUHN H, KLus H: Reduction of smoke nicotine and smoke condensate in Austria during the past fifteen years. Fachl Mitt Oesterr Tabakregie 16:320-329, 1975

(26) TodD GF: Changes in smoking patterns in the U.K. In Proceedings of the Eleventh International Cancer Congress, Florence, Italy, 1974, occasional paper I. London: Tobacco Research Council, 1975

(27) Timm VJ: Trendanalysen zum Problem des Verbrauches an Nikotin und Rauchkodensat in der Bundesrepublik Deutschland für die Jahre 1961 bis 1975. Beitr Tabakforsch 8:404-414, 1976

(28) ADAMS PI: Changes in personal smoking habits brought about by changes in cigarette smoke yield. In Proceedings of the Sixth International Tobacco Scientific Congress, Tokyo, Japan, 1976. Coresta Information Bull (special):102-108, 1976

(29) Freedman S, Fletcher CN: Changes of smoking habits and cough in men smoking cigarettes with $30 \%$ NSM tobacco substitute. Br Med J 1:1427-1430, 1976

(30) Russell MA, Wilson C, Patel VA, et al: Plasma nicotine levels after smoking cigarettes with high, medium, and low nicotine yields. $\mathrm{Br}$ Med J 2:414-416, 1975

(31) Department of Health, Education, and Welfare: Teenage smoking: National patterns of cigarette smoking, ages 12 through 18, 1972 and 1974. DHEW Publ No. HSM 76-931. Washington, D.C.: U.S. Govt Print Off, 1976

(32) Williams CL, Wynder EL: A blind spot in preventive medicine JAMA 236:2196-2197, 1976

(33) Williams CL, Arnold CB, Wynder EL: Primary prevention of chronic disease beginning in childhood: The 'know your body' program: Design of study. Prev Med 6:344-357, 1977

(34) SCHWARTz JL: A critical review and evaluation of smoking control methods. Public Health Rep 84:483-491, 1969

(35) SHewchuck LA: Smoking cessation programs of the American Health Foundation. Prev Med 5:454-474, 1976 